\title{
UN PROYECTO DE GAUDI EN CHILE
}

\section{Christian Matzner T.}

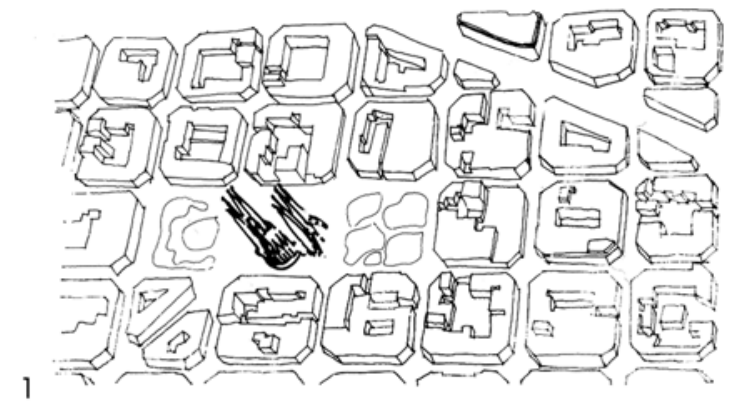

El deseo de construir en Rancagua, Chile, una capilla diseñada por Gaudí, originalmente para el Templo de la Sagrada Familia en Barcelona, y con el visto bueno de éste, dado hace ya 74 años.

There is a desire to construct a chapel in Rancagua, Chile, which was originally designed for the Sacred Family Temple in Barcelona by Gaudi. Gaudi approved this project 74 years ago.

a historia de este proyecto se remonta al año 1922. cuando el padre Angélico Aranda (1), de la Orden Franciscana de Rancagua, Chile, escribió al arquitecto catalán Antonio Gaudí -a quien había conocido en 1909- pidiéndole un proyecto para hacer una "Pequeña Capilla o Santuario dedicado a Nuestra Señora de los Angeles o Porciúncula", en Rancagua

"Por medio del secretario de la Junta del Templo, Juan Martí Matlleu, Gaudí contestó que no podia dedicarse a otra obra que no fuera la Sagrada Familia , pero que meditando sobre las medidas que el padre Aranda le había enviado se había apercibido de que casi coincidían con el Edículo proyectado en la parte posterior del ábside del templo dedicado a la Virgen de la Sagrada Familia, de ta manera que bastaba copiar lo que ya se había estudiado y resuelto para el templo y mandarlo Chile(...). El señor Martí Matlleu tuvo que ausentarse de Barcelona y, luego de la muerte de Gaudi en 1926, el encargo chileno quedó en manos de Domingo Sugrañes y, aunque no se llevó a cabo la idea de Gaudí, quedó constancia de las buenas relaciones de éste con el Padre Aranda en un cuadro de tema religioso que se envió desde Chile a Barcelona y que se conservó en el estudio de la Sagrada Familia hasta el incendio de 1936", (2).

De visita en Barcelona, el padre Angélico quedó impresionado por lo hermoso de su arquitectura y en especial del Templo de la Sagrada Familia, que en 1909 tenía en plena construcción la fachada del Nacimiento (en 1912 los campanarios llegaban a los 60 metros):

"Admiré asimismo un templo, cuya construc ción lleva cerca de treinta años, el cual será una de las maravillas de la arquitectura moderna. Es de estilo gótico, pero tan original, que supera con creces a muchos monumentos de su género. Yo subi hasta la mitad de su altura y hube de ascender 250 gradas. No le doy más detalles por la sencilla razón de que el tiempo no me permitió examinar toda la obra. Todos los extranjeros que la visitan se desatan en alabanzas del arquitecto que la dirige y no tienen empacho en afirmar que él es un genio. Yo lo traté y tuvo la singular bondad de darme su firma, que yo. por cierto, reputo como una de las más importantes de mi libreta", (3).
En 1922 le escribe a Gaudi encargándole formalmente un proyecto para hacer la capilla referida, pero, como se señaló, todo quedó enterrado en el tiempo, sin embargo el destino es impredecible.

El profesor George R. Collins (1917-1993), gran gaudinista estadounidense, intentó encontrar antecedentes sobre este proyecto, en diversos viajes a Chile, pero sin obtener resultados.

En 1973 fueron catalogados en el índice de la "Cátedra Gaudí" los documentos relacionados con este caso -encontrados por un estudiante- producto de la reordenación de los Archivos Diocesanos de Barcelona. Lamentablemente no pudo prosperar ninguna gestión o iniciativa al respecto. En Barcelona nadie recordaba que en Chile existiera un arquitecto que hubiera gestionado esta información, llevándola de Barcelona a Rancagua. Sólo se pudo averiguar a través del Padre Jaime Aymar Ragolta, actual delegado Diocesano para los Medios de Comunicación Social del Arzobispado de Barcelona, sobre un grupo de laicas catalanas de la Asociación "Grup Claraeulàlies" radicadas en Chile, las que a través del Sr. Nicolás Díaz, senador de la Región, y de su hijo, el doctor Rodrigo Díaz, habían hecho intentos al respecto, apoyadas por el arquitecto Cristián Barahona de la I. Municipalidad de Machalí y otras personalidades de la Región interesados en este proyecto.

En forma paralela a lo anteriormente descrito en junio de 1995, a un mes de retornar a Chile, y terminando un curso de doctorado en la "Cátedra Gaudi" de la Universidad Politécnica de Cataluña en Barcelona, el profesor director del curso, don Juan Bassegoda i Nonell, nos comenta de esta apasionante historia, sobre la que él escribió un artículo en su libro "El Gran Gaudí"(4) y nos encomienda "desenterrarla": "„Vea usted que puede hacer!"

Contactamos así, con el padre Jaime Aymar, y con Jordi Bonet Armengol, Arquitecto, Director y Coordinador de la Junta Constructora del "Temple Expiatori de la Sagrada Familia" a través del arqui-

Luego de algunas reuniones con el padre Aymar y, siguiendo el rastro de la referencia biblio gráfica del artículo del profesor Bassegoda. se encuentra en los Archivos Diocesanos de Barcelona -en los envoltorios de carpetas enpolvadas y enveecidas por el tiempo-, precisamente las dos cartas intercambiadas entre el padre Aranda y el arquitecto Gaudí: fechada la del padre Aranda, el 15 de agosto de 1922, y la respuesta de Gaudí, a través del secretario de la Junta del Templo, Juan Martí Matlleu, el 12 de octubre de 1922.

Este descubrimiento valoró y dio autenticidad a todo lo investigado hasta el momento. De todos los documentos encontrados apareció una lista de donaciones de distintas entidades y personalidades para ayudar al financiamiento del Templo de la Sagrada Familia, entre los cuales aparece una donación de fray Angélico Aranda. La donación aparece destacada con color rojo. Se cree que ese destacado pudo ser de la mano de Gaudí o del Sr. Martí Matlleu, resaltando la donación de 177 Pesetas, valor claramente superior al resto de las donaciones.

Templo de la Sagrada Familia y su impacto urbano en la trama de Barcelona. tecto en obra, Jordi Faulí.

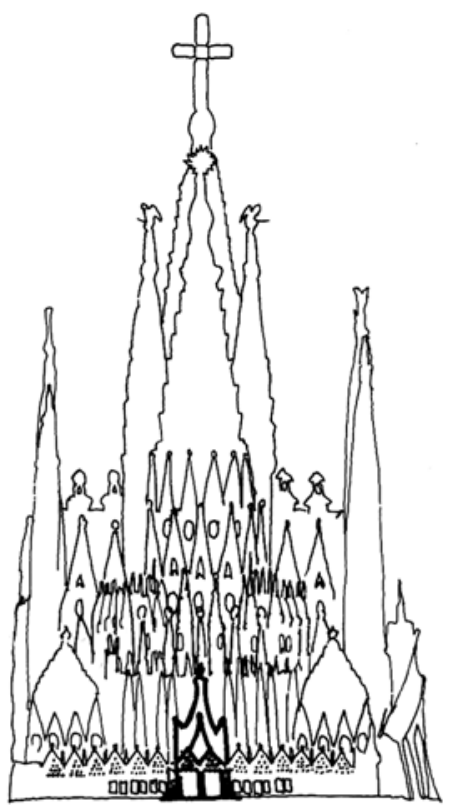

Esta donación viene a confirmar que la relación entre el padre Aranda y Gaudí iba más allá que un simple autógrafo, constituyendo un verdadero compromiso para con la gran obra arquitectónica del alarife.

Paralelamente a estas gestiones, nos reunimos con el arquitecto en obra de la Sagrada Familia, Jordi Faulí, planteándole el caso y solicitándole información sobre el tema, tanto gráfica como escrita. Con el Arqto. Faulí estudiamos el edículo en cuestión, analizando la maravillosa arquitectura propia de la geometría reglada (leyes de la naturaleza que Gaudí estudió, entendió y supo aplicar en su obra). Recorrimos los actuales trabajos en obra imaginando la capilla de la Asunción, su forma constructiva y su relación con el ábside, que Gaudí alcanzó a ver antes de su muerte.

Después de otras reuniones, la Junta Constructora decidió entregarnos planos de la Capilla de la Asunción, para lo cual solicitó oficializar formalmente dicha entrega mediante un acto de recepción suscrito.

Además de los planos, se aportaron dos fotografias de dibujos originales de Gaudí del Edículo, y la memoria del proyecto "La Capella de L' Assumpta en el temple de la Sagrada Familia" realizados por los Aratos. Lluis Bonet Gari, Francesc Cardoner Blanch e Isidre Puig Boada (5).

Aparte de esta importante colaboración, el Arqto. Faulí manifestó el interés de la Junta Constructora en materializar la construcción del mencionado edículo en Chile, y en la búsqueda de algún croquis o dibujo original de Gaudi en nuestro país, lo que se basa en lo dicho en la carta de Martí Matlleu al padre Aranda (6)

Además, frente a la posibilidad de que se construyera el proyecto en Chile, se planteó el interés en establecer una comunicación entre arquitectos de ambos países, mediante el sistema "Internet", uniendo los terminales de la Universidad Politécnica de Cataluña y de la Universidad de Chile. El intercambio de información de Diseño y Técnica, materializaría la idea de vincular las relaciones Chile-España tanto en el plano histórico como en el tecnológico.

Entendiendo la importancia de asentar en Rancagua una capilla diseñada con el "visto bueno" de Antonio Gaudi, y a modo de formalizar un compromiso de Cataluña con esta noble empresa, se consiguieron cartas de apoyo de: Jordi Bonet Armengol, Arato. Director y Coordinador de la Junta Constructora del "Temple Expiatori de la Sagrada Familia"; Jaime Aymar Ragolta, del Arzobispado de Barcelona; María Teresa Rosés Magnoni, Presidente de la Fundación Catalunya América, y Juan Bassegoda i Nonell, Catedrático de Historia de la Arquitectura y de Urbanismo, Jardinería y Paisaje, y Director de la Cátedra Gaudí de la Universidad Politécnica de Cataluña.

El Templo Expiatorio de la Sagrada Familia, algunos antecedentes.

- 1822 -1883. Primer proyecto e inicio de la cripta: F. de P. del Villar i Lozano.

- 1884-1926. Revisión del proyecto y dirección

2. Alzado posterior Templo Sagrada Familia destacando Capilla de la Asunción. 


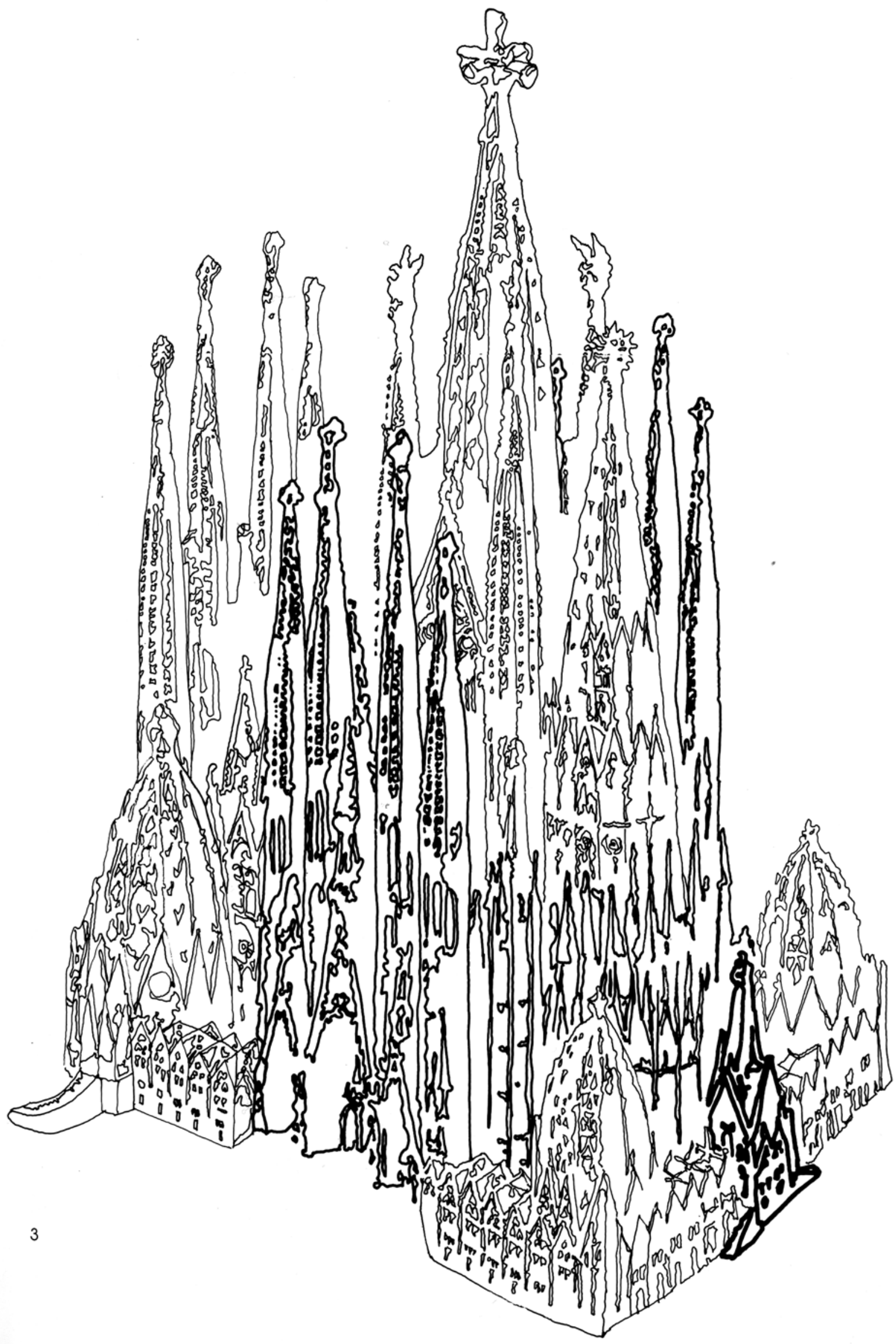

de las obras (cripta, ábsides y fachada del Nacimiento): Antoni Gaudí i Cornet.

- 1927-1935. Continuación de las obras según proyecto de Gaudí : D. Sugrañes i Gras.

- 1939-1950. Restauración de la cripta: F. Quintana i Vidal.

- A partir de 1951. Proyecto y dirección de la fachada de la Pasión: F. Quintana i Vidal Luis Bonet i Garí, Isidre Puig Boada. Francesc de Paula. Cardoner i Blanch (desde 1961).

- 24 julio 1969. Declarado Monumento Histórico-Artístico de Interés Nacional.

Es un templo inacabado y que actualmente está en construcción, de significado único e irrepetible por sus cualidades formales y espaciales, representa en sí mismo el resumen concentrado de toda la obra y estudio arquitectónico del genial Antonio Gaudi Cornet.

La descripción del templo dada en "Arquitectura de Barcelona" de J.F. Hernández Cruz y otros (7), nos resume perfectamente las ideas y características:

"Gaudí inició su intervención en el Temple de la Sagrada Familia construyendo la cripta (1882 1891). Partía de un proyecto inicialmente diseñado por F. de P. del Villar, del que se iría alejando progresivamente, reconduciéndolo hacia unos planteamientos mucho más ambiciosos y creativos. Así, actúa sobre el modelo gótico de planta basilical con cinco naves, crucero y un amplio ábside con deam bulatorio, introduciendo innovaciones, que en planta son periféricas y que consisten principalmente en rodear toda la fábrica con un deambulatorio exterior -que Gaudí denominó impropiamente clustre- $y$ en el sobredimensionado de los grandes portales que se abren en los dos extremos del crucero y en los pies de la iglesia, dedicados al Nacimiento, la Pasión y la Gloria de Cristo, respectivamente. De los tres, solamente terminó el de levante (fachada del Nacimiento, 1891-1900) en cuya resolución plástica se pone de manifiesto su concepción expresionista de la forma que, a diferencia de lo que sucede en otras obras suyas, aqui se presenta distorsionada por un vehemente misticismo".

En la fig. 1, podemos entender el tamaño e impacto a nivel urbano que significa dicho templo actualmente, tanto para el barrio del "Eixample". como para toda la ciudad de Barcelona. En relación a la altura total del templo acabado, será la "cruz gaudiana" de cinco aspas, un gran mirador del puerto ja 170 metros de altura! (la cúspide de San Pedro del Vaticano, en Roma tiene 150 metros). Dicha imagen la podemos observar en la fig. 3, tomada de una perspectiva de Francisco Valls, donde hemos dibujado con líneas de grosor intermedio, lo que actualmente está construido; con líneas algo más delgadas, lo que sería el templo totalmente acabado -con su cimborrio central de 170 metrosy, con líneas muy gruesas, la Capilla de la Asunción. la cual estaría en el centro de eje mayor del templo. en el punto medio del ala $\mathrm{N}-\mathrm{O}$ del claustro, junto al ábside.

En relación a las distintas opiniones relativas a la continuación de las obras del templo, es preciso el siguiente alcance: por un lado, está un grupo de 


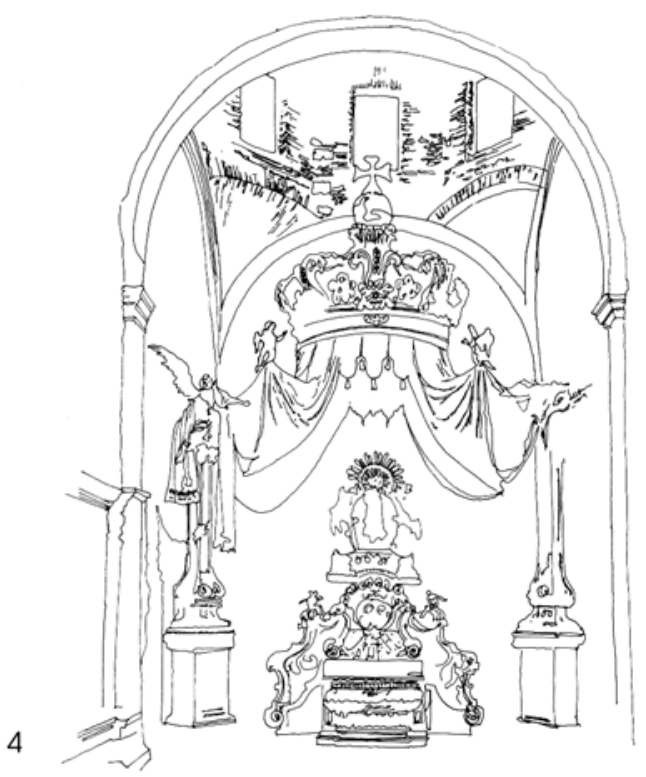

críticos a la continuación de las obras, que plantean que al morir Gaudí en 1926, la construcción debió ser detenida.

Otro grupo piensa que las obras se deben continuar, pero sostienen una cierta crítica a la forma en que actualmente se está haciendo.

Finalmente, están los que piensan que se debe terminar y que se está haciendo perfectamente.

En relación a esta discusión, debemos manifestar que creemos que el templo se debe terminar por las siguientes razones:

-łoda obra arquitectónica es concebida para ser terminada y, por tanto, usada:

-hay una necesidad psicológica de la población -tanto catalana como mundial- de ver materializada una obra de esta connotación y, finalmente, en honor a Gaudi, sin duda, él sabía que no podría terminarla, y que otros la continuarían hasta su total término (8).

\section{La Capilla de la Asunción}

De acuerdo a lo ya explicado anteriormente sobre la ubicación de éste edículo tras el ábside. Gaudí lo concibió como un pequeño pero importante volumen en el centro del eje mayor del templo. Se dice que lo ideó como "un recuerdo del adorno popular de las fiestas de la virgen de Agosto y sugerida posiblemente por la obra del escultor Bonifac que existe en la Catedral de Girona "(9).

Dicha obra barroca de Lluis Bonifac (1730-1786). de los años 1772-75, es Ilamada "Llitera de la Mare de Déu d'Agost" , y la vemos en la fig. 5 (10).

Basada en los túmulos de velos y cortinas que cubren la figura yaciente de la Virgen, Gaudi dibujó unos croquis a mano alzada -como siempre trabajaba él, junto a sus maquetas - de la Capilla de la Asunción (fig. 6), donde se descubre en su mágico trazo, las formas de parábolas, paraboloides hiperbólicos, hiperboloide y otras formas compuestas (11).

Con respecto al término definitivo de la construcción del Templo de la Sagrada Familia, se ha estimado por el aparejador R. Espel, de la Junta Constructora, que el fin de obras será para el año 2045 (!), sin embargo ésta es una fecha tentativa, sujeta a confirmación .

En relación a las prioridades de la obra, se nos explicó que al estar actualmente finalizadas las fachadas del Nacimiento, de la Pasión, la cripta y el ábside, se ha dado continuidad a las naves, las cuales están avanzando en paralelo en columnas, bóvedas, ventanales y cubiertas.

Por tanto, se estima que una de las últimas obras por realizar, será el claustro el cual circundará el templo, sirviendo de comunicación entre portales, capillas y sacristías. "Al circundar el templo, permite la circulación de procesiones, a la vez que lo separa del ruido exterior" (12)

De ello se desprende que la Capilla de la Asunción, probablemente será una de las últimas obras ha realizarse en el Templo de la Sagrada Familia de Barcelona.

Por tanto, de materializarse en Rancagua (Chile), una capilla como ésta, será no sólo relevante
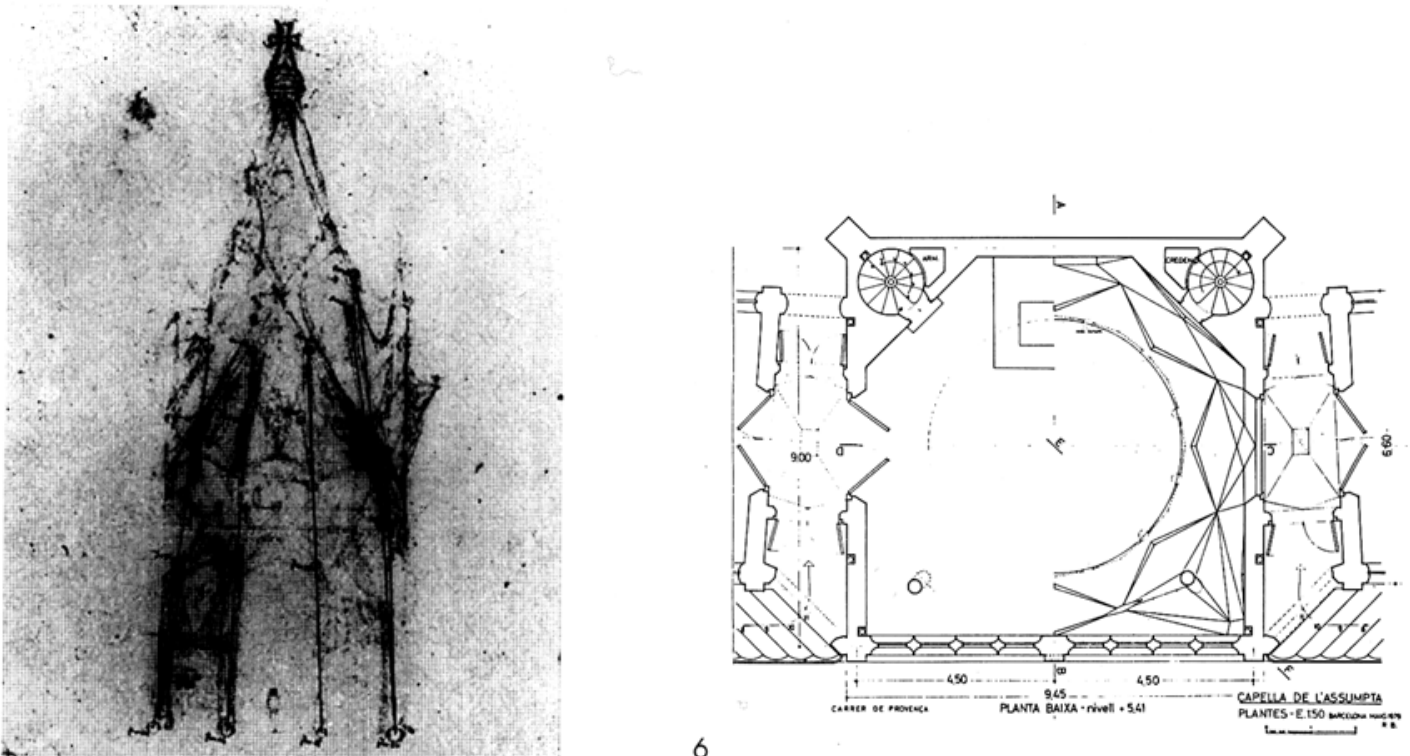

para la Comunidad de los PP. Franciscanos, sino también para la comunidad internacional de arquitectos, por su condición de modelo-ejemplo de lo que en el futuro se haría en Barcelona.

También se puede entender el rol jerárquico que tiene su ubicación tanto en planta como en alzado,ordenando las circulaciones y accesos de todo el Templo desde la calle Provenza, como en alzado, donde se puede observar la proporción del cimborrio central que tendrá 170 metros de altura con el edículo de 30 metros; además se descubre que la proporción del edículo -relación entre la altura de la cúpula y corona con los hastiales, los rosetones, capiteles y formas helicoidales- con la del Templo propiamente tal -relación entre el cimborrio central y los Párticos, ábside, sacristías y capillas- son correspondientes.

Existe una relación entre la Capilla de la Asunción y la parte inferior de los cimborrios dedicados a la Virgen María (sobre el ábside) y a Jesucristo (sobre el crucero) además de la cripta. Podemos de tectar que Gaudí ideó la capilla en forma integrada a su entorno; no obstante, su arquitectura com pacta, la define como un volumen, un edículo to talmente independiente del resto. Es decir, entendida en planta como un cuadrado, podemos decir que la capilla tiene cuatro fachadas, lo que en definitiva facilita su concepción como edificio aislado, para efectos de su construcción en Rancagua, Chile.

\section{Gestiones para su construcción en Chile}

Con fecha 8 de abril de 1996, se ha dado un paso histórico en el camino emprendido, al constituirse legalmente en un acto solemne en la ciudad de Rancagua, la "Corporación Gaudí de Triana" (13) la cual es una institución de derecho privado, con personalidad jurídica y sin fines de lucro.

Sus objetivos serán:

a) la construcción y mantenimiento de una capilla en Rancagua dedicada al culto y bajo la tuición de la Iglesia Católica, correspondiente a edículo denominado "Capilla de la Asunción"del templo de la Sagrada Familia de Barcelona, España, diseñada por el arquitecto Antonio Gaudí;

b) la construcción, mantenimiento y cuidado de una casa de carácter religioso y cultural, bajo la tuición de la Iglesia Católica, que acoja a toda persona, en especial a intelectuales y artistas -sin distinción de creencias religiosas o ideológicas- que busquen un espacio de soledad y silencio que facilite el reencuentro consigo mismo y con los valores más auténticos del ser humano, y

c) la difusión y el estudio de la obra del arquitecto español Antonio Gaudí, con el respaldo de la "Cátedra Gaudi", de la Universidad Politécnica de Cataluña.

\section{REFERENCIAS}

1. Fray Angélico Aranda nació en Linderos en 1870, y a los 16 años ingresó a la congregación ordenándose sacerdote en 1894. Además ra. Para profundizar sus habililidades artisticas, viajó a Europa pintudo a Roma en 1908. Alli perfeccionó lo aprendido con sus maestros Chile tray Angélico visitó distintas ciudades españolas Madrid Tnar a Avila y Bar (a)

2. BASSEGODA i NONELL, Joan, El Gran Gaudí, Barcelona, Editorial AUSA, 1989, p. 581

3. Revista Serófica de Chile agosto de 1909,pp. 524-525.

4. BASSEGODA i NONELL, Joan, Op.cit., .58 ?

5. En 1954 los arquitectos I.Puig B. y LI. Bonet G., son nombrados miembros de la Junta Constructora y colaboraron con Quintana para poder dirigir la obra, y sucediéndole después de su muerte, en el año 1966. Las figuras $6,7,8$ y 9 , corresponden a los planos que nos entregó la Junta Constructora de la Sagrada Familia.

6. En relación a esto, gracias a la amable colaboración del padre Rigoberto lturriaga C., del Convento de San Francisco de Asís de Santiago, para una exhaustiva búsqueda, hemos podido comprobar que. al menos en los Archivos del Convento de Avda. Bernardo O'Higgins. no hay croquis ni planos originales de Gaudi.

7. Ver: HERNANDEZ CROS, J.E.; MORA, G.; POPUAPLANA, X., Arquitectura de Barcelona, Barcelona, Colegio de Arquitectos de Barcelona, 1990. pp. 278-279,

8. Es preciso tomar conciencia que muy pocas catedrales medievaes eran iniciadas y terminadas por el mismo arquitecto, siendo éstas traspasadas de generación en generación, e incluso, en algunos casos, de un estilo a otro, como, por ejemplo, del romántico al góti$\mathrm{Co}$, etc.

9. En: BONET i ARMENGOL, Jordi, Temple Sagrada Familia, Barcelona, Editorial Escudo de Oro, S.A., 1992, p.76.

10. Aparece en: CALZADA i OLIVARES, Josep, Catedral de Girona Barcelona. Editorial Escudo de Oro, S.A., 1979.

En: BARRAL I ALTET, Xavier, Les Catedrals de Catalunya, Barcelona. Edicions 62, 1994:

"Tot Just s'accedeix a les sales del museu de la catedral, ubicades a espectacularitat i teatralitat la Litera de la Mare de Déu d'Agost. Aquesta peca, obrada per Uuis Bonifac i Massó, respon al costum.

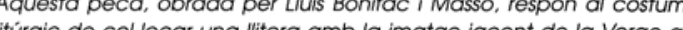
' A belmig da

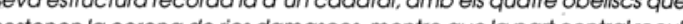

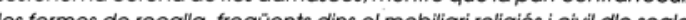
les formes derocala frec

11. El significado religioso y simbólico de todo el ediculo y su descripBonet G., Francesc Cardoner B. e Isidre Puig B., en el documento "La Capella de la Assumpta" y/o "Capilla dedicada a Ntra. Sra. de los Angeles $\circ$ Porciúncula", Asociación "Grup Claraeulàlies" "Rosenmann-Danilo-Matzner Arquitectos Asociados", documento de trabajo inédito, Rancagua. Chile, 1995.

12. En: BONET i ARMENGOL, Jordi, op.cit., p. 26.

13. El nombre "...de Triana", proviene de la fundación de la ciudad de Rancagua en 1743, por José Antonio Manso de Velasco, con el fifulo de Villa de Santa Cruz de Triana, en recuerdo del nombre de un barrio de Sevilla, España. El Consejo de Administración lo conforman: Presidente, Sr. Nicolás Díaz (Senador VI Región): Vicepresidente, la Asociación "Grup Claraeulàlies" (laicas católicas catalanas); Sr. Javier Prado, Obispo Diocesano: Sr. Ricardo Tudela,Gobernador Provincial de Cachapoal; Sr.Esteban Vaienzuela, Alcalde de la I. M. de Rancagua; Sr.Carlos Muñoz, SEREMI Vivienda y Urbanismo, VI Región: Sr.Fernando Troncoso, Presidente Regional del Colegio de Arquitectos de Chile, A.G.: Dr. Sr.Rodrigo Díaz (uno de los primeros promoto(es), y Cristian Matzer. Arquitecto representante de la "Cótedro Gaudi". de sus labores regulares como fraile. desarrollaba el arte de la pintuchilenos Pedro Lira y Juan Francisco aprólez. Antes de maestros les antigues dependències canonicals. Ens sorprèn per la sevo ción completa, la tenemos traducida de los textos en catalán de Lluis 

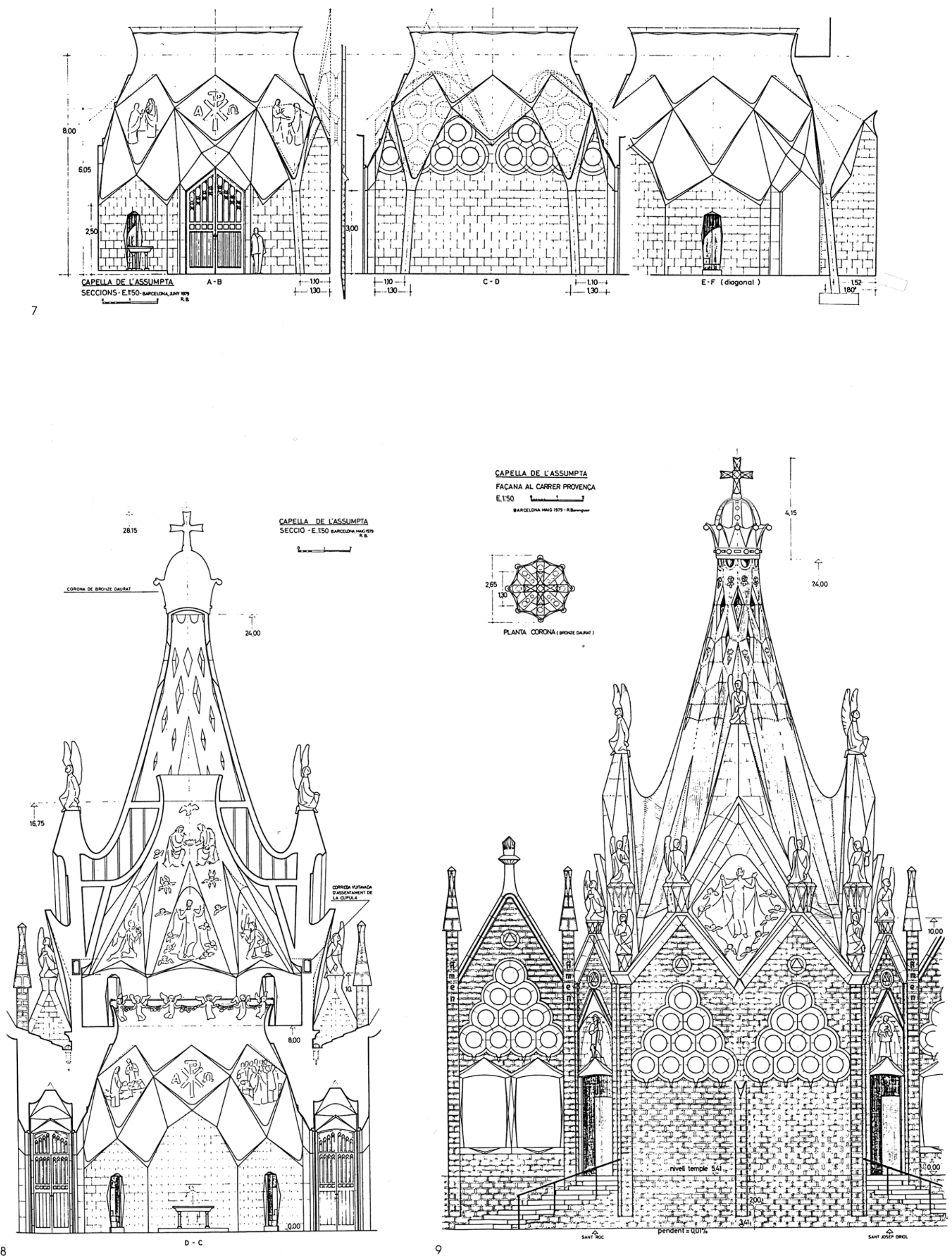